\title{
Structural Test and Analysis of a Hybrid Inflatable Antenna
}

\author{
James L. Gaspar* \\ NASA Langley Research Center, Hampton, Virginia, 23681, USA \\ Troy Mann ${ }^{\dagger}$, Tham Sreekantamurthy ${ }^{\ddagger}$, and Vaughn Behun ${ }^{\S}$ \\ Swales Aerospace, Hampton, Virginia, 23681, USA
}

\begin{abstract}
NASA is developing ultra-lightweight structures technology for communication antennas for space missions. One of the research goals is to evaluate the structural characteristics of inflatable and rigidizable antennas through test and analysis. Being able to test and analyze the structural characteristics of a full scale antenna is important to enable the simulation of various mission scenarios to determine system performance in space. Recent work completed to evaluate a Hybrid Inflatable Antenna concept will be discussed. Tests were completed on a 2-m prototype to optimize its static shape and identify its modal dynamics that are important for analytical model validation. These test results were used to evaluate a preliminary finite element model of the antenna, and this model development and correlation activity is also described in the paper.
\end{abstract}

\section{Introduction}

PACE antenna development has been driven by several important factors such as reflectivity, shape accuracy,

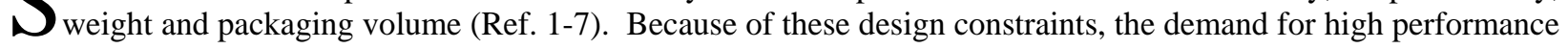
antennas has increasingly stimulated the development of inflatable and deployable antennas since they can achieve a low weight and small packaging volume and maintain high shape accuracy (Ref. 8). The antenna shape accuracy, which is defined as the degree to which the actual shape of the structure equals the intended shape, is an important factor affecting the electromagnetic performance of the antenna.

During the development of new antennas, many structural research studies and laboratory experiments have been performed to predict and reduce reflector surface distortions (Ref. 9-11). For gossamer structures, analytical characterizations of on-orbit shape distortions (Ref. 12-17) are important because the space environment is difficult to simulate on the ground. Ground testing limitations include the difficulties of simulating support-free operation and control under extremely low structural loadings brought on by zero-gravity conditions of space, as well as the inherent difficulty that full scale gossamer antennas may not be able to withstand high loads in the ground environment. Despite these difficulties laboratory testing on the ground before flight is important for verifying the geometrical shape of the fabricated antenna, providing experimental data for verification of structural analyses, and confirming operation of the inflation and deployment mechanisms. Recent laboratory tests of gossamer structures such as inflatable and deployable antennas and solar sails have focused on measurement of their static and dynamic characteristics using photogrammetric techniques (Ref. 18-20). In parallel with these analytical and ground testing advances in shape prediction and measurement, the antenna manufacturers have sought improvements in the fabrication process to precisely contour the surfaces of the reflectors (Ref. 21-28). These three approaches, analytical studies, laboratory tests and fabrication techniques, by themselves or in combination, are used to ensure that the antenna design margins, antenna shape errors, and structural mass are held to acceptable limits in the development of high precision antennas.

NASA Langley Research Center (LaRC) is developing ultra-lightweight structures technology for antenna and space solar power applications for NASA missions (Ref. 17 and 29), with one of the research goals being the

\footnotetext{
* Aerospace Engineer, NASA Langley Research Center, Hampton, Virginia, AIAA Member

${ }^{\dagger}$ Aerospace Engineer, Swales Aerospace, Hampton, Virginia, AIAA Member

‡ Aerospace Engineer, Swales Aerospace, Hampton, Virginia, AIAA Member

$\S$ Aerospace Engineer, Swales Aerospace, Hampton, Virginia, AIAA Member
} 
evaluation of structural characteristics of inflatable and rigidizable antenna structures through test and analysis. As part of this goal, LaRC, in collaboration with NASA Glenn Research Center (GRC), is evaluating inflatable and rigidizable antennas for deep space applications.

\section{Test Article}

A Hybrid Inflatable Antenna (HIA) concept is being investigated at LaRC to determine its structural characteristics. The HIA is a parabolic reflector that operates at the $8.4 \mathrm{GHz}$ NASA deep space network frequency. The antenna provides a backup rigid antenna within the inflatable dish. The inflatable reflector annulus greatly increases the antenna area. A dual feed ensures operation of the smaller fixed dish throughout the mission providing a "risk buffer" to the inflated dish. The prototype consists of a 0.5 meter diameter rigid reflector surrounded by a 2m-diameter inflatable and then rigidizable annulus (see Figures 1 and 2). The inflatable annulus has a radio frequency (RF) transparent canopy on its upper surface to aid in pushing the lower RF reflector into its ideal shape during deployment. The RF reflector of the annulus incorporates a shape memory polymer (SMP) composite layer that is used to help deploy the dish and then is rigidized in its deployed state. Inflation gas is not necessary once fully deployed and rigidized. The outer rim is an inflatable and rigidizable torus structure that is used to hold the outer circumference of the annulus in tension at its catenary attachment points.

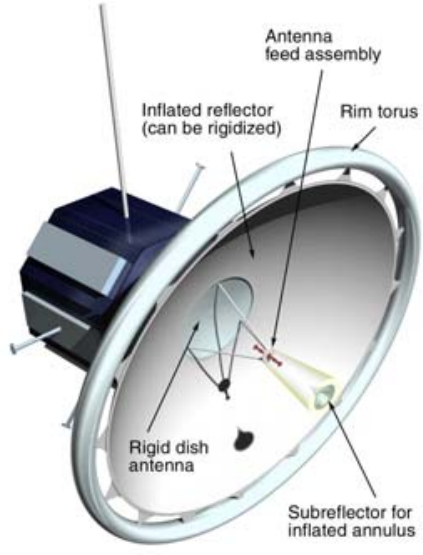

Figure 1: Deployed Hybrid Inflatable Antenna

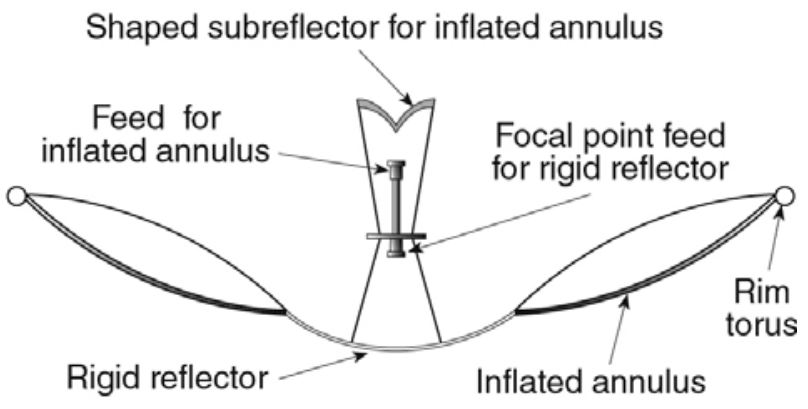

Figure 2: Cross-sectional View Showing HIA High Efficiency Feed Concept

The 2-meter HIA test article, shown in Figure 3, was fabricated as a result of collaboration between ILC Dover Inc., and Applied Physics Lab (APL) (see Ref. 25, 26). The deployable annulus is made of a SMP material of 0.181 $\mathrm{mm}$ thickness, which is aided during deployment by inflation at a nominal internal pressure of $60 \mathrm{~Pa}$. The inflated annulus is held stretched by 32 elastic (spring) catenaries that are equally spaced around the circumferential edge of the dish (Figure 4). Each spring carries a nominal tension load of $31.1 \mathrm{~N}$ and is secured by a rigid oval torus frame.

Recently, LaRC completed tests to measure the static shape and structural dynamic response characteristics of the HIA 2-meter test article. In parallel with this activity, a pre-test structural analytical model was developed using design details and material properties provided from ILC Dover. This paper presents the details of the structural characterization tests to determine the static shape and modal dynamics of the antenna at its nominal catenary tension $(31.1 \mathrm{~N})$ and inflation pressure loads $(60 \mathrm{~Pa})$. These test results are then compared to the pre-test structural analytical model to identify inaccuracies in the model and determine ways to improve it. 


\section{Test Measurements}

\section{A. Static Shape Test}

To provide measurement locations for static shape and dynamic tests, approximately 100 retro-reflective targets were placed on the backside surface of the SMP annulus. The retro-reflective targets were used to provide good signal response when illuminated with flash photography for photogrammetry or with a laser for laser Doppler vibrometry. A professional photogrammetry camera was used to precisely measure the 3-dimensional position of each of these targets when the structure was inflated to the operational pressure of $60 \mathrm{~Pa}$. Figure 3 shows the 2meter antenna as equipped for the static tests. Static shape measurements were obtained for two test configurations, first with the dish in a cup-down configuration and then with the dish facing cup-up. For each test configuration, 75 pictures were taken at various positions with each image capturing a portion of the test article in the field of view. In each image are special identifier targets recognized by the post-processing photogrammetry software to enable piecing the images together. These coded targets along with calibrated scale bars are used to insure high quality data (Figure 5). A $31.1 \mathrm{~N}$ weight was hung from one of the catenary springs to determine the spring elongation under the nominal load. The attach points of each catenary spring on the support frame was then adjusted to the desired spring length that would produce the nominal boundary load $(31.1 \mathrm{~N})$ for the antenna. This technique provided a uniform stress boundary condition that was significantly improved compared to the initial setup.

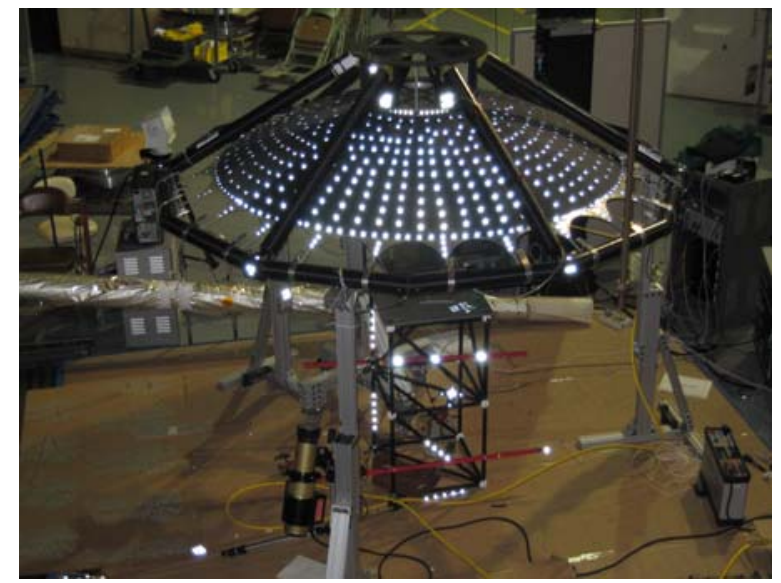

a) Cup-Down Test

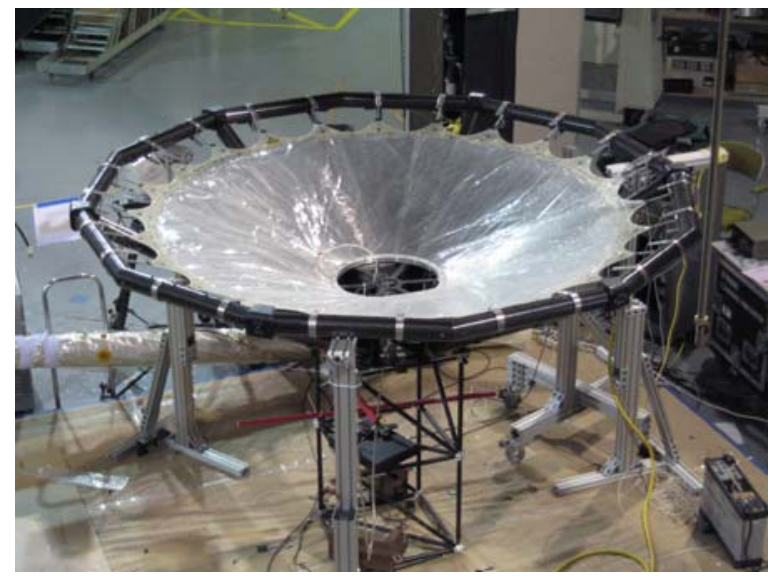

b) Cup-Up Test

Figure 3: 2-meter Antenna Test Configurations

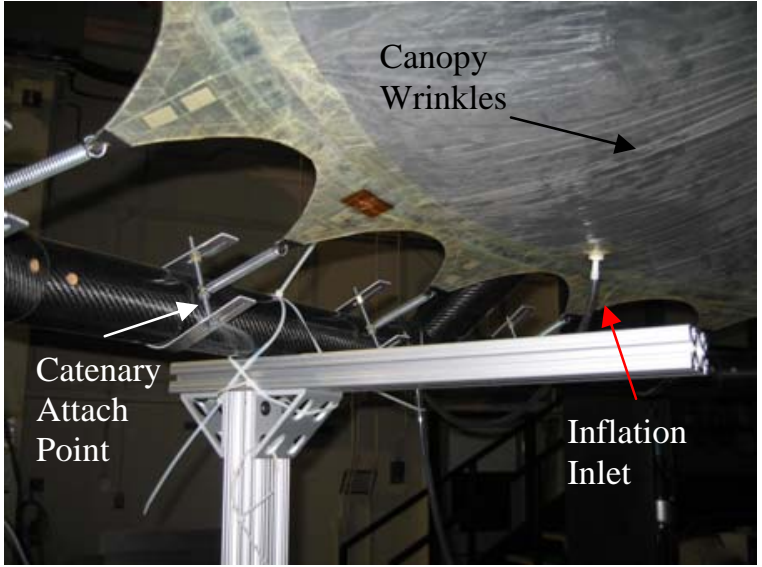

Figure 4: Catenary Attach Point to Adjust Load (Also Seen is Inlet for Inflation)

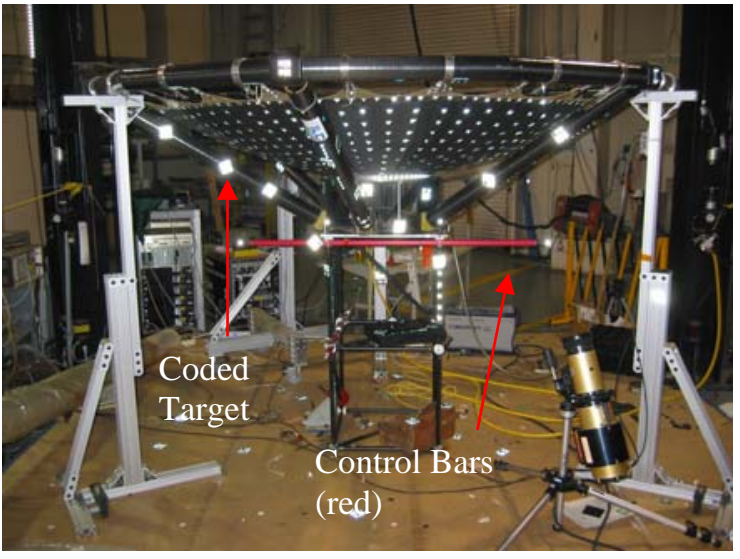

Figure 5: Control Bar \& Coded Targets Used for Photogrammetry 
The test static shape results were then compared with the ideal analytical dish shape, and the deviation from this idealized shape was calculated (Figure 6). It was found that for the test configurations measured, we obtained a 2.2 $\mathrm{mm}$ root-mean-square (RMS) deviation from the ideal dish shape for the cup-down configuration and a $6.1 \mathrm{~mm}$ RMS deviation for the cup-up configuration. The higher distortion for the cup-up configuration is likely due to increased deflection of the test article under gravity load. The catenary springs had been precisely adjusted while in the cup-down configuration, and no further optimization was performed when the dish was placed in the cup-up configuration. Evaluation of the shape deviation color contour plot shows several shallow indentations that could also be visually identified in the SMP dish in its deflated state, but is less pronounced visually while inflated. These indentations could only be partially removed with increased inflation pressure and they appeared consistently for both cup-down and cup-up configurations. Deviation from the ideal shape is also shown near the central hub and outer circumference areas. Examination of the test article confirmed some local bulging of the dish in these areas, caused by seams and small imperfections at the interfaces.

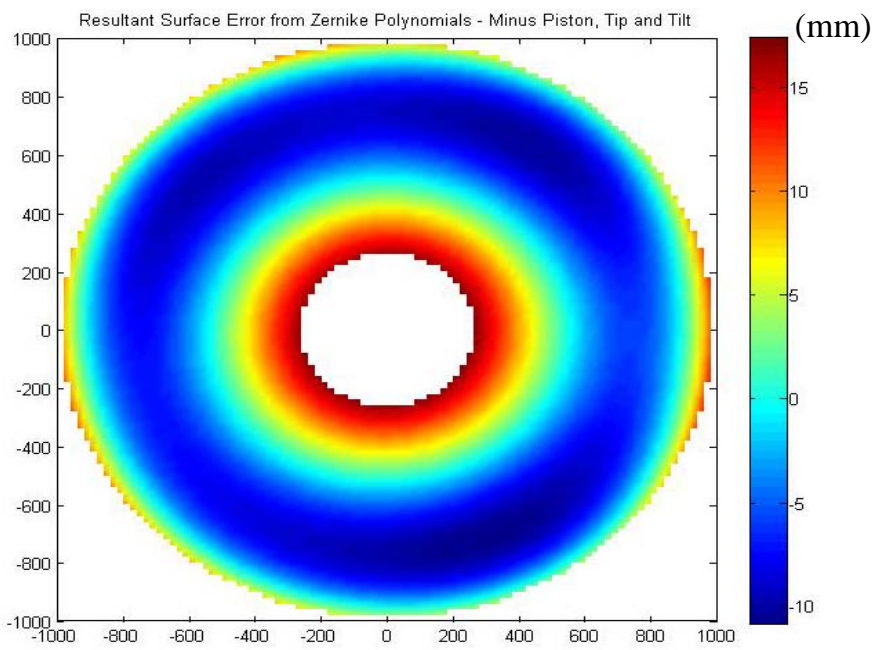

a) Cup-Down Test

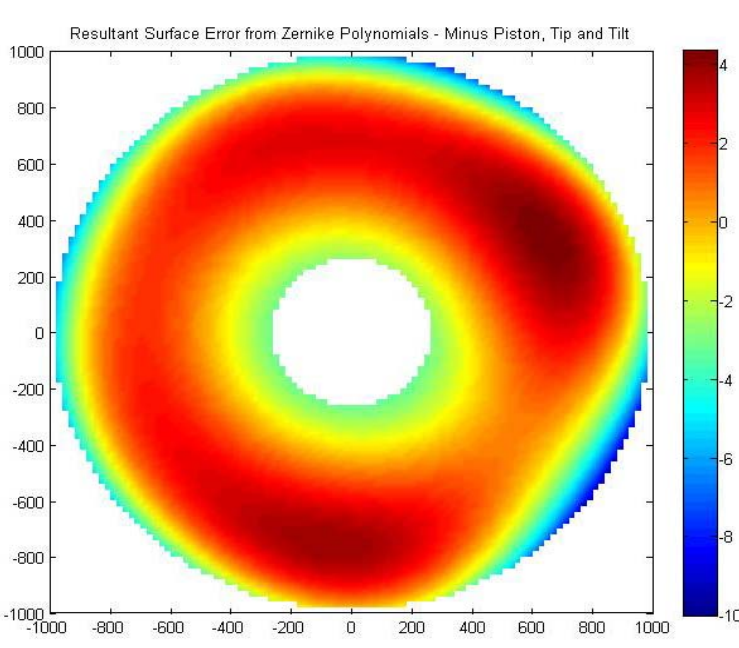

b) Cup-Up Test

Figure 6: Test Static Shape Deviation from Ideal Dish Contour - 2-meter antenna

\section{B. Dynamic Test}

Dynamic measurements were made on the antenna using the retro-reflective targets with a scanning laser doppler vibrometer. The tests were completed for two basic configurations; first with the dish cup facing down, then with the cup facing up. In both configurations vibrometer responses are measured with the laser vibrometer configured $\sim 7$-meters directly above the test article (Figures 7 and 8). For the cup down configuration, high spatial resolution data was obtained since the bottom surface of the SMP composite dish had many retro-reflective targets placed on its surface. For the cup up configuration, only measurements were obtained along the outer circumference of the dish near the catenaries. For both configurations, measurements were also made on the support frame torus. All measurements were made in ambient conditions inside the NASA-Langley Structural Dynamics Branch High Bay Test Facility. Excitation was provided with a $5 \mathrm{lb}$. shaker attached to the test article through a nylon stinger with a $10 \mathrm{lb}$. load cell glued to the test article. Tests were completed with direct shaker excitation to the dish near various catenary attachment locations, as well as frame excitation to better identify the frame response modes for the system (Figure 9). Non-contacting electromagnetic excitation was also completed, to evaluate its performance against direct shaker excitation. For this test, an electromagnet was positioned within $5 \mathrm{~mm}$ of the test article and centered over a small metal strip that would react to electromagnet signal inputs. For all the dynamics tests the excitation was provided in the form of periodic chirp or pseudo-random inputs from 0 to $100 \mathrm{~Hz}$ and 3 averages. All of the mode shapes shown in this paper have been obtained by curve-fitting, using the ortho-polynomial curve-fitting procedure in the Vibrant Technology Me'scope modal analysis software package. 


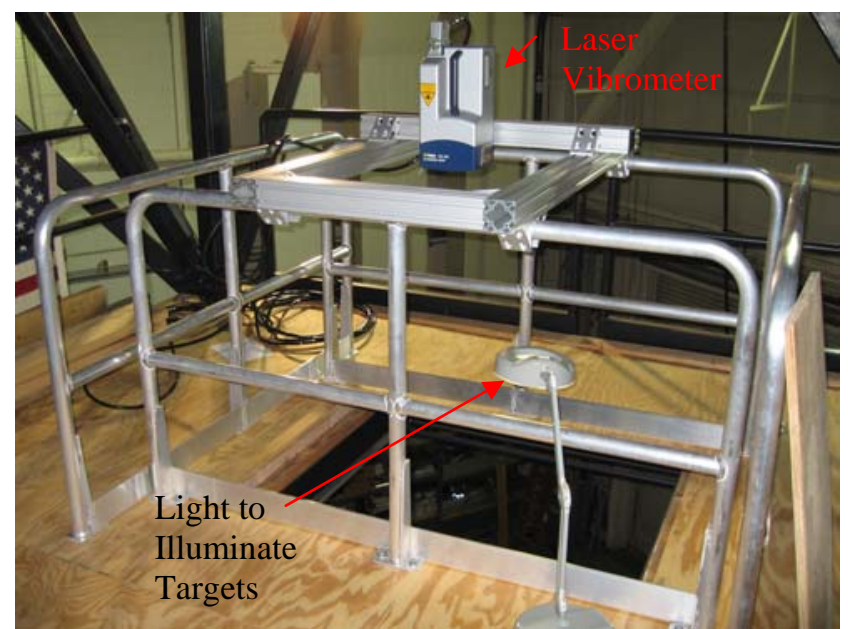

Figure 7: Laser Vibrometer Above Test Article With Light to Illuminate Targets

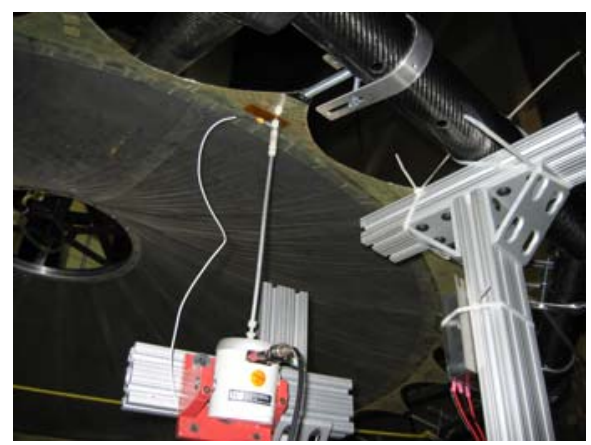

a) Cup-Down Dish Excitation with a Shaker

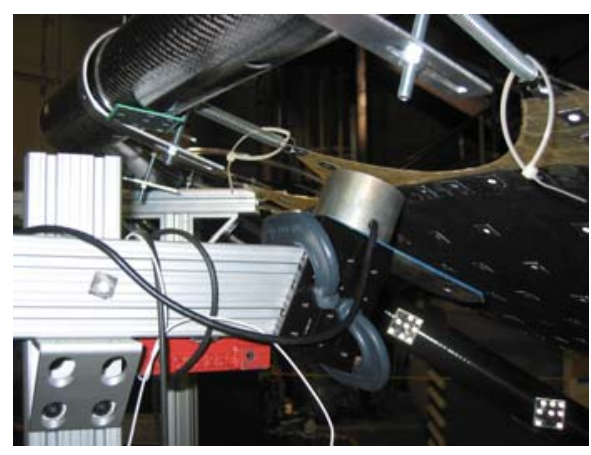

c) Cup-Up Dish Excitation

with Non-contacting Electromagnet

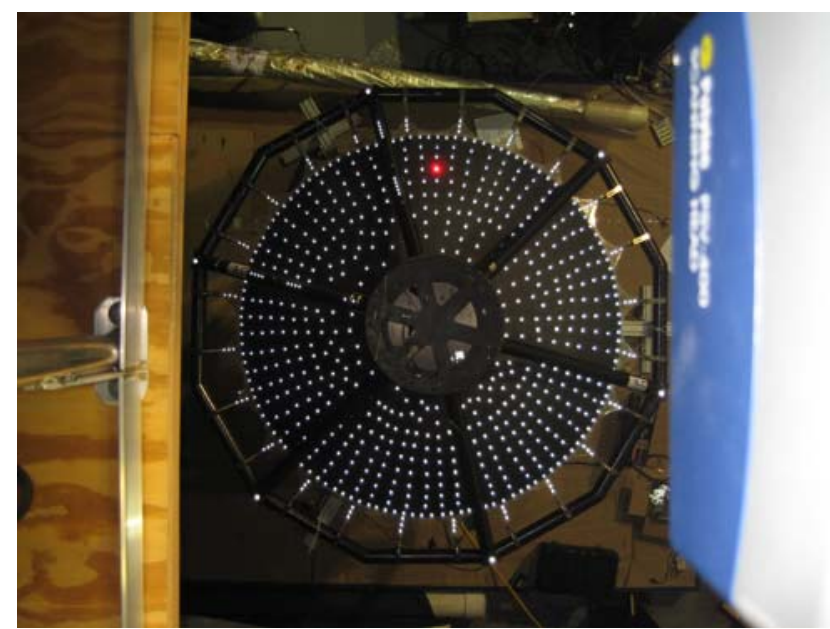

Figure 8: View from Laser Vibrometer

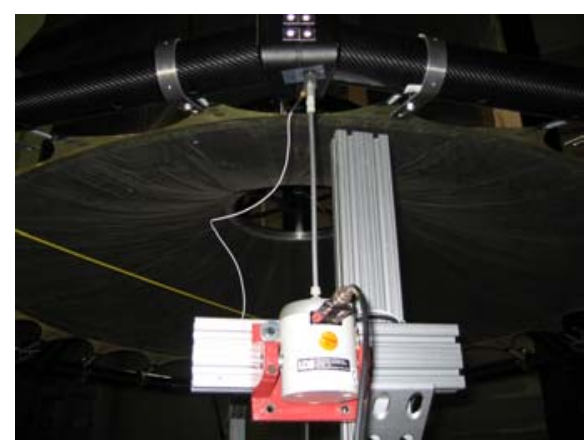

b) Cup-Down Frame Excitation with a Shaker

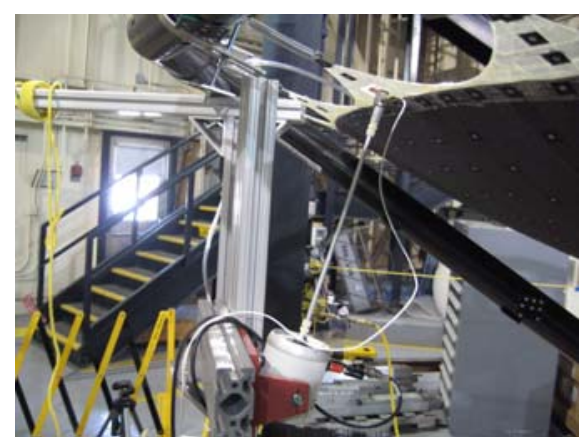

d) Cup-Up Dish Excitation with a Shaker

Figure 9: Test Article Excitation Configurations 


\section{Shifting in Mode Shape Anti-node with Shaker Excitation Location}

The first test completed on the antenna was for the cup down configuration with the catenary tension at the nominal $31.1 \mathrm{~N}$ and the inflation pressure at $50 \mathrm{~Pa}$. In this configuration the dish was excited directly at various catenary locations. Figure 10 shows the Average Spectrum (average of all measurements) Frequency Response Function (FRF) and coherence (COH) from direct dish excitation at a catenary location. The FRF shows 4 well defined modes with good $\mathrm{COH}$ at resonance. The first mode $(8.8 \mathrm{~Hz})$ is a $2^{\text {nd }}$ order bending mode with two orthogonal node-lines passing through the dish centerline, so that the dish folds inward (i.e. like a taco). The second mode (9.6 $\mathrm{Hz}$ ) is a $3^{\text {rd }}$ bending mode with three node-lines passing through the dish centerline. Likewise, the third mode (10.7 $\mathrm{Hz})$ is a $4^{\text {th }}$ bending mode of the dish. The fourth mode $(12.6 \mathrm{~Hz})$ is dominated by a dish tilt motion with $5^{\text {th }}$ order bending of the dish around the circumference. These four modes were found to repeat very precisely for the three shaker locations chosen. However, it was noted that the anti-nodes for each mode shape would shift to coincide with the shaker location for each test (Figure 11). This shifting in mode shape anti-node with excitation location even occurred with non-contacting magnetic excitation, so it is not due to mass or stiffness loading from the shaker. It may be due to a non-linearity introduced via the catenary arrangement and possibly by the wrinkles on the upper canopy (Fig. 4) of the dish that extend outward in all direction along the radial line. Analytical studies were conducted that indicated that canopy wrinkling can have a major effect on the dynamics, including substantial frequency shifts (see section IV for analytical study).

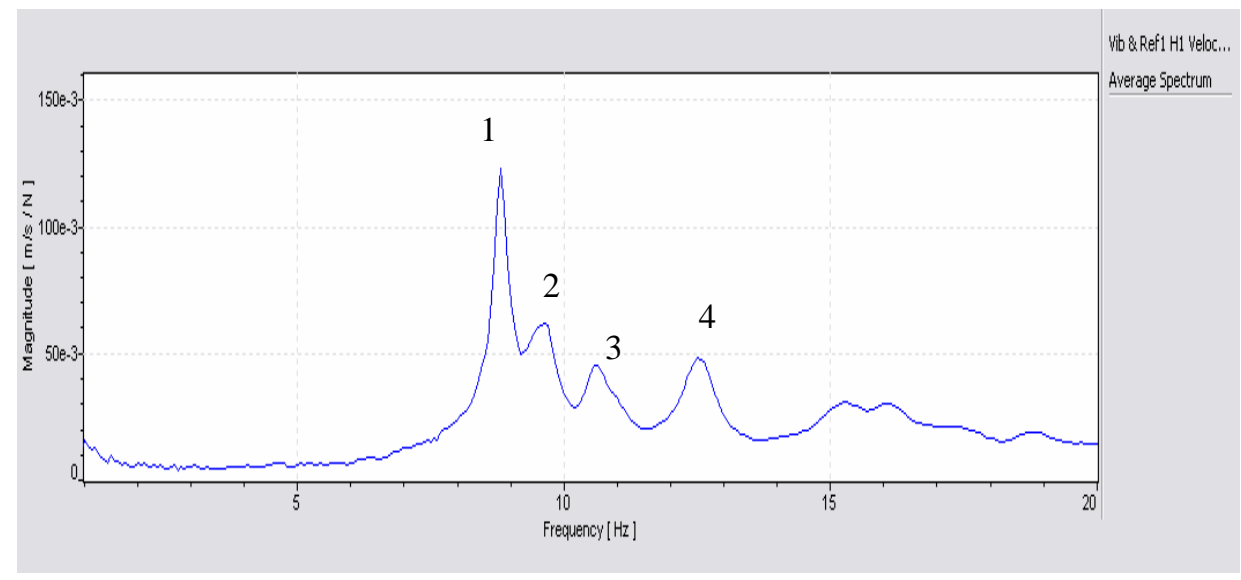

a) Average Spectrum FRF

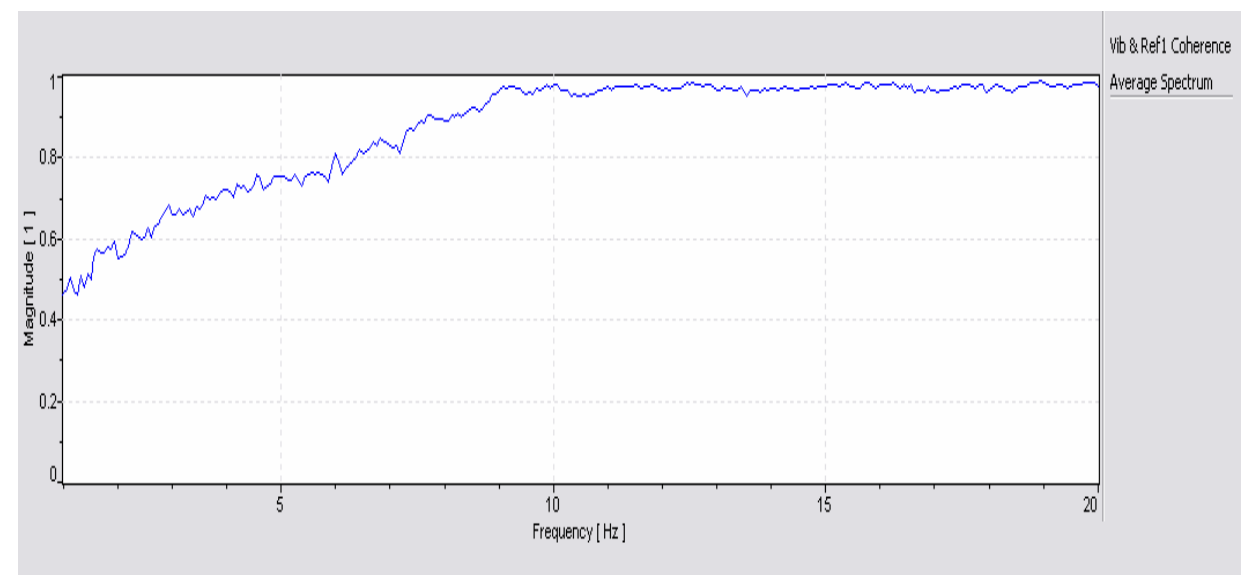

b) Average Spectrum Coherence

Figure 10: Average Spectrum FRF and Coherence from Dynamics Test (Cup Down Configuration) 


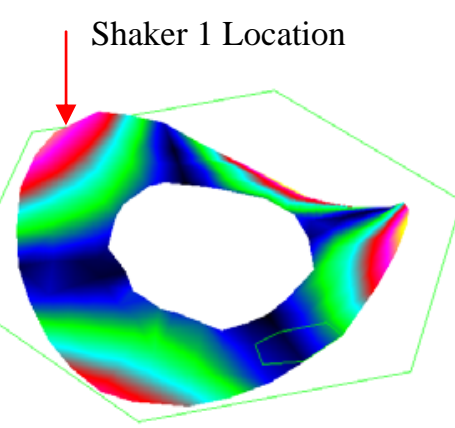

a) $8.8 \mathrm{~Hz}$ 2nd Bending, Shaker 1

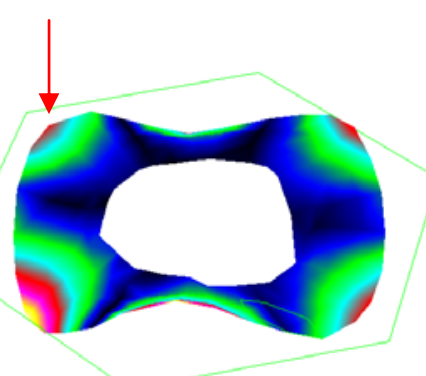

d) $9.6 \mathrm{~Hz} 3^{\text {rd }}$ Bending, Shaker 1

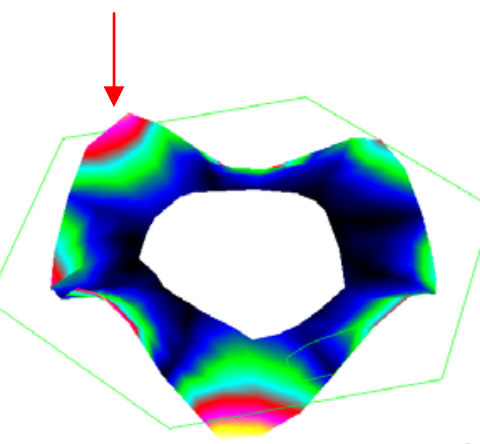

g) $10.7 \mathrm{~Hz} 4^{\text {th }}$ Bending, Shaker 1

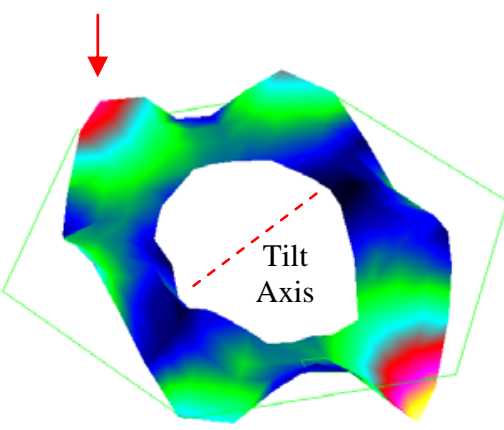
j) $12.6 \mathrm{~Hz}$ Tilt/5 ${ }^{\text {th }}$ Bending, Shaker 1
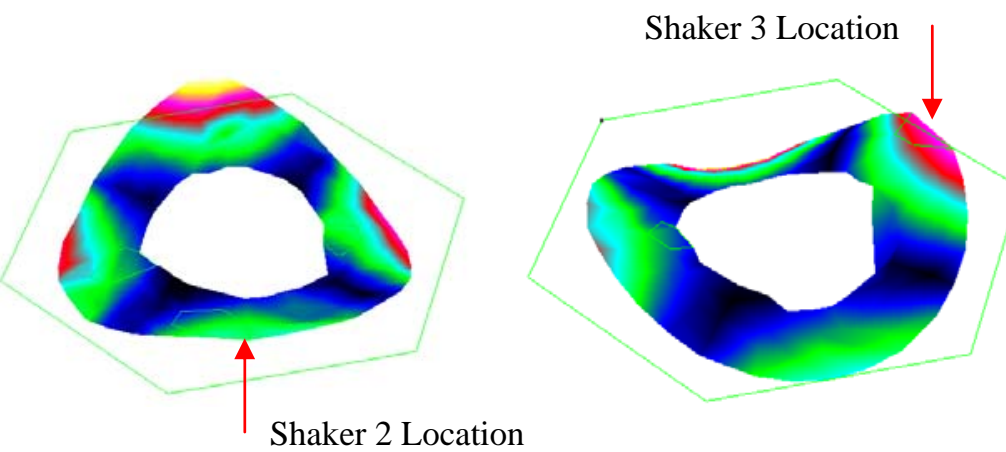

b) $8.9 \mathrm{~Hz}$ 2nd Bending, Shaker 2

c) $8.9 \mathrm{~Hz}$ 2nd Bending, Shaker 3
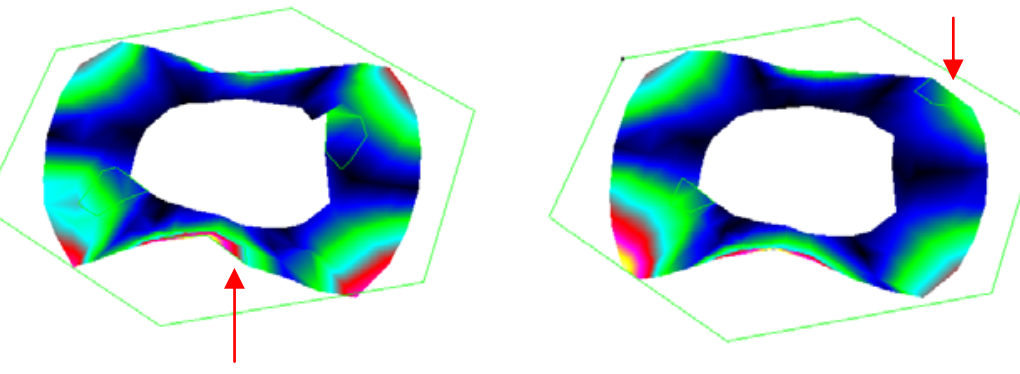

e) $9.6 \mathrm{~Hz} 3^{\text {rd }}$ Bending, Shaker 2

f) $9.7 \mathrm{~Hz} 3^{\text {rd }}$ Bending, Shaker 3
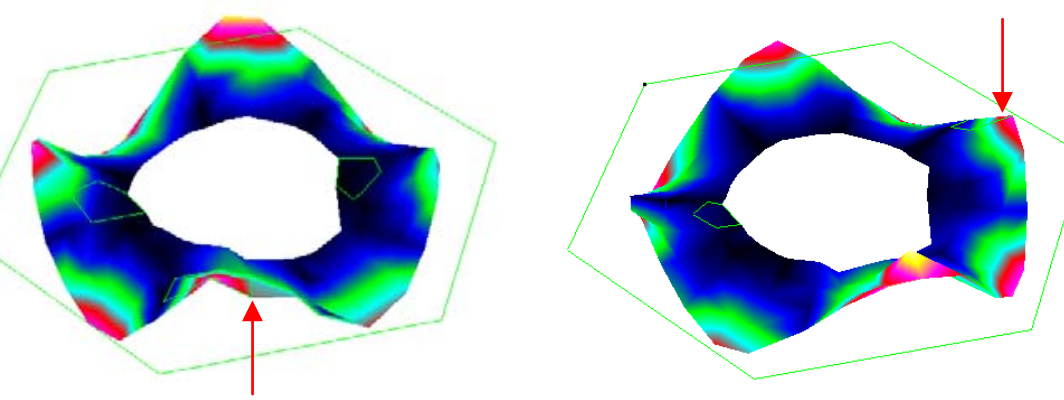

h) $10.7 \mathrm{~Hz} 4^{\text {th }}$ Bending, Shaker 2

i) $10.9 \mathrm{~Hz} 4^{\text {th }}$ Bending, Shaker 3

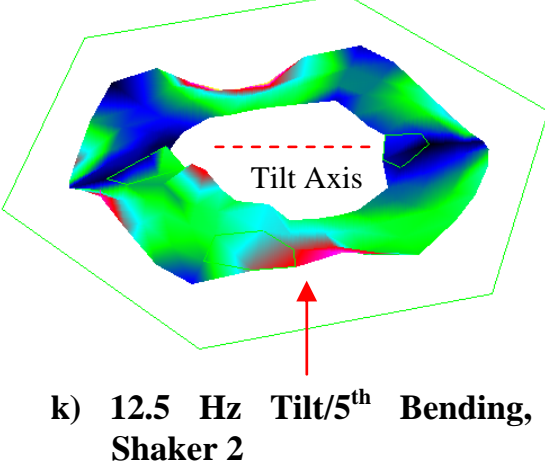

l) $12.3 \mathrm{~Hz} \mathrm{Tilt} / 5^{\text {th }}$ Bending, Shaker 3

Figure 11: Changes in Mode Shape with Shaker Location (Cup-Down Configuration, Red Arrow Indicates Shaker Location on Dish) 


\section{High Spatial Resolution Mode Shape Identification}

Several tests were completed using all the available retro-reflector targets on the bottom surface of the dish to gather the highest spatial resolution data (584 measurements) possible to better identify the mode shapes being excited. These tests take a significantly longer time to perform (7 hours vs. 1.6 hours), so only a few were completed. The tests were for the cup down configuration, with the dish at the nominal $31.1 \mathrm{~N}$ catenary tension and $60 \mathrm{~Pa}$ inflation pressure. This higher spatial resolution data allowed for the identification of an additional three modes beyond what was previously identified. These modes continued the trend of increased bending around the circumference of the dish from $5^{\text {th }}$ order (Figure 12) to $7^{\text {th }}$ order bending. However, all these modes exhibited some dish tilt motion. The lower spatial resolution tests also identified the dish tilt motion of these modes, but failed to capture the bending around the dish circumference very well because of the poor shape resolution. Figure 13 shows the modes were well excited as seen in the average response spectrum FRF and coherence. The mode shape for mode 7 (identified in Figure 13a) at $17.4 \mathrm{~Hz}$ is very complicated, involving major frame tilt motion as well as dish tilting and what appears to be $7^{\text {th }}$ order bending around the dish circumference. The $17.4 \mathrm{~Hz}$ mode is the first one to have major frame tilt motion, with the frame pivoting on the three support stands.

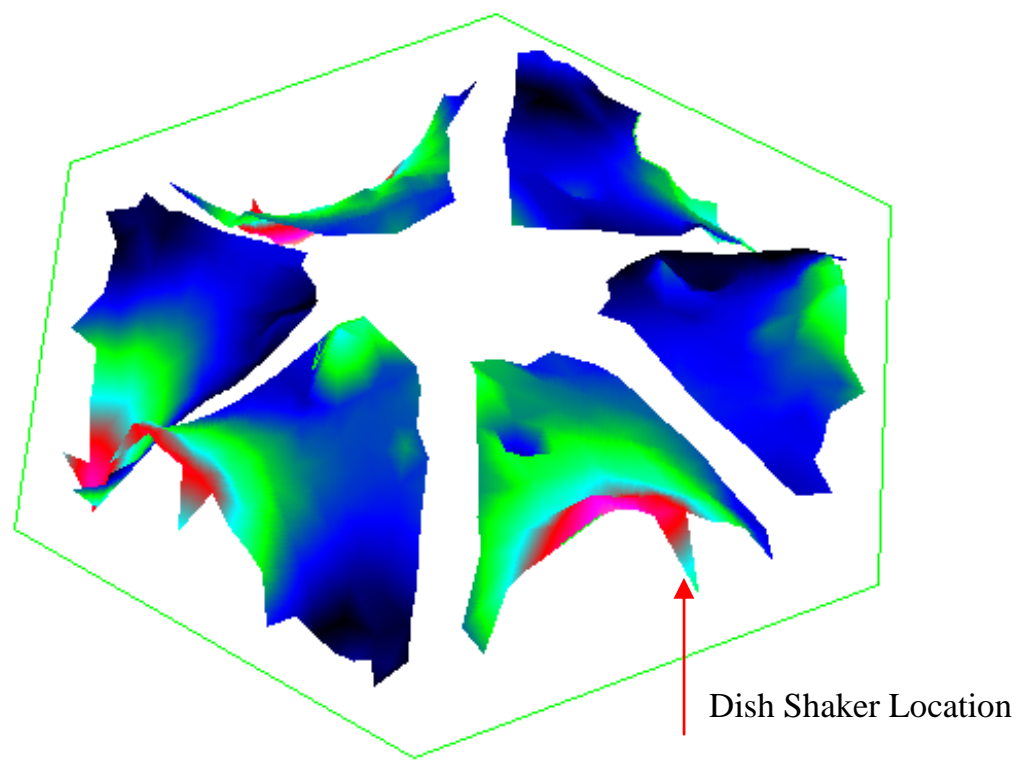

Figure 12: 12.9 Hz Dish Tilt with Dish $5^{\text {th }}$ Bending Mode Shape (Cup-Down Configuration, High Spatial Resolution Test)

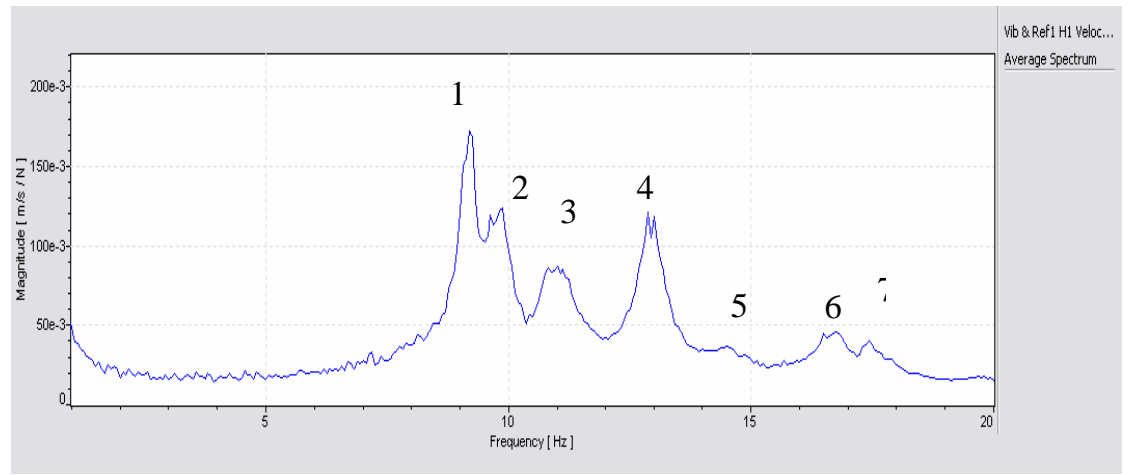

a) Average Spectrum FRF 


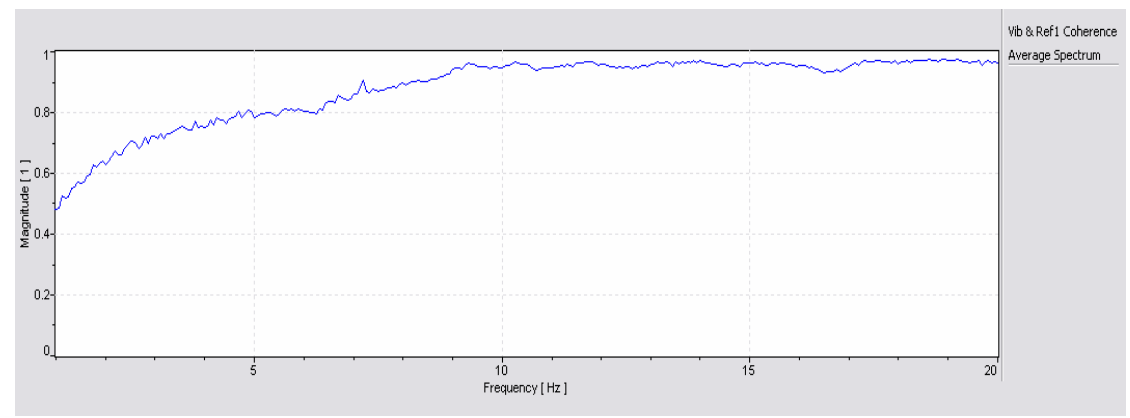

b) Average Spectrum Coherence

Figure 13: Average Spectrum FRF and Coherence from Dynamics Test (Cup-Down Configuration, High Spatial Resolution Test)

\section{Frame Excitation test with Dish Attached}

A test was completed with excitation provided directly to the frame with the dish still attached via catenaries, to better identify the resonances of the frame-dish system. Once again the dish was in the cup-down configuration at the nominal $31.1 \mathrm{~N}$ catenary tension and $50 \mathrm{~Pa}$ inflation pressure. Only the first dish bending mode $\left(8.9 \mathrm{~Hz}, 2^{\text {nd }}\right.$ bending) could be identified with frame excitation (Figure $14 \mathrm{a}$ ). The $3^{\text {rd }}, 4^{\text {th }}$, and $5^{\text {th }}$ bending modes appeared only as predominately tilt motion in these mode shapes. This can be expected because these are predominately dish modes that are not very well excited by frame excitation. Examination of the drive point FRF shows strong resonance at $17.3 \mathrm{~Hz}$ for the frame (Figure 15). The $17.3 \mathrm{~Hz}$ mode shape shows the dish in tilt motion with little visible bending around the circumference (Figure 14b). For the higher order modes, the frame starts to couple with the dish and dominate it with a tilting response motion.

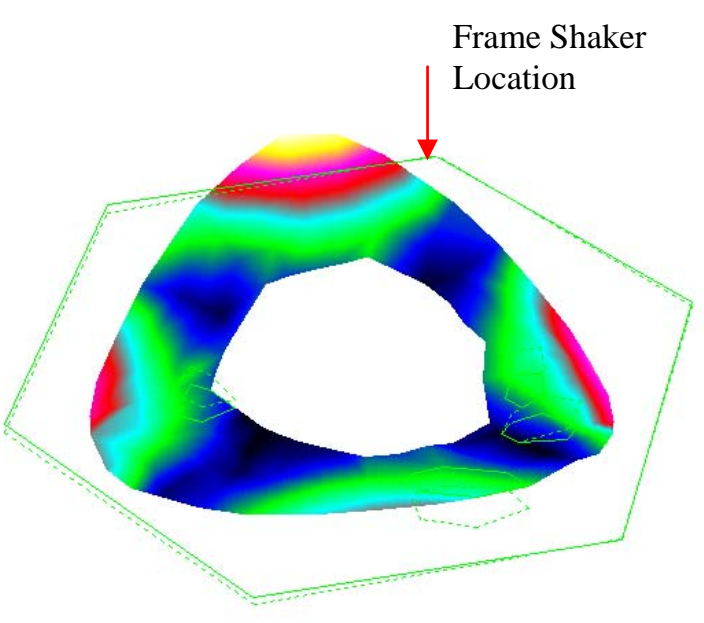

a) $8.9 \mathrm{~Hz} 2^{\text {nd }}$ Bending

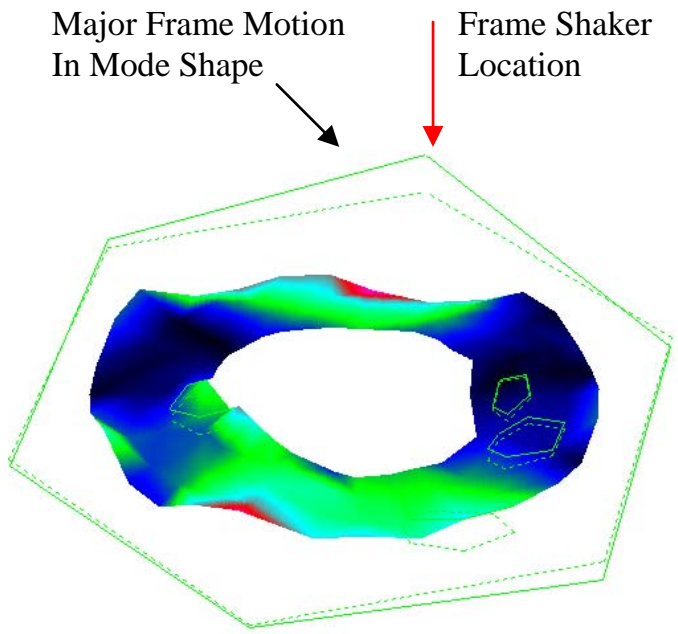

b) 17.3 Hz Frame \& Dish Tilt

Figure 14: Mode Shapes from Frame Excitation Test (Cup-Down Configuration) 


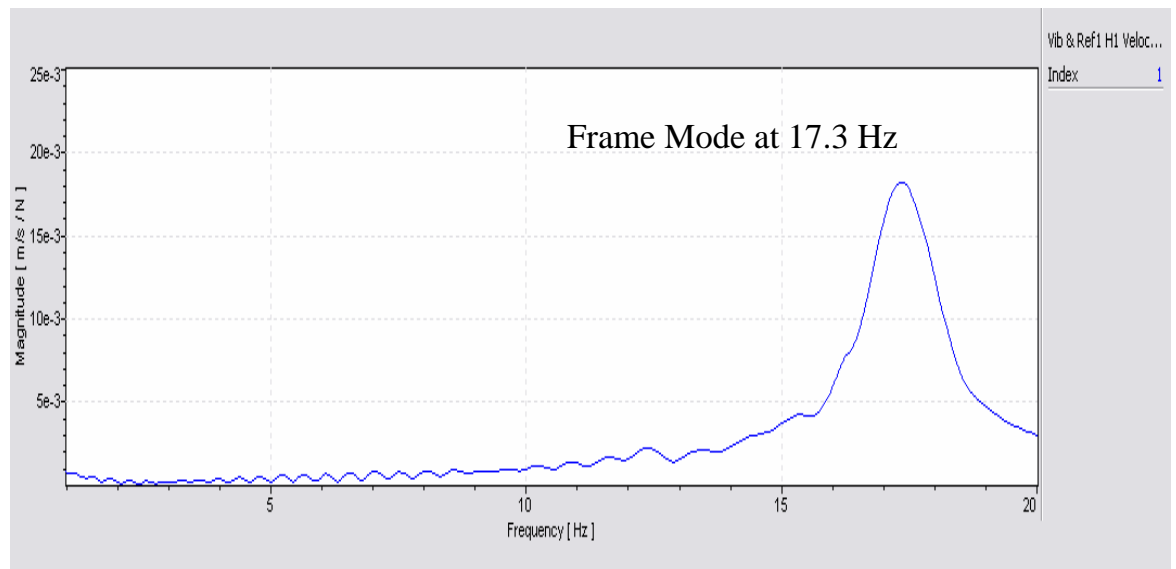

a) Drive Point FRF

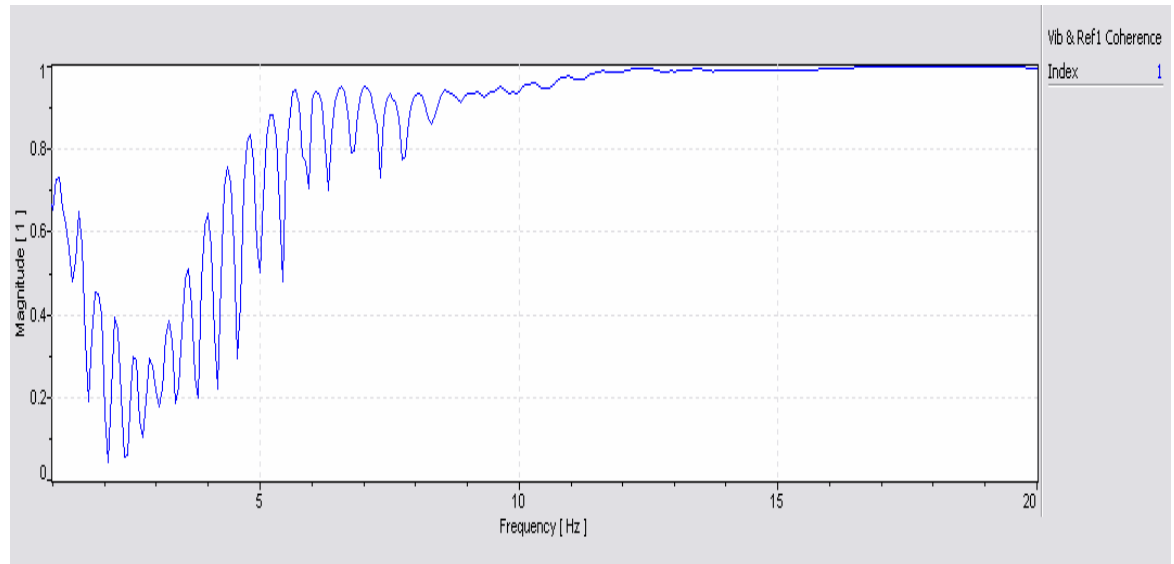

b) Drive Point Coherence

Figure 15: Frame Drive Point FRF and Coherence (Frame Excitation Test, Cup-Down Configuration)

\section{Cup-Down versus Cup-Up Dynamic Response Comparison}

After the frame test, the antenna was flipped over into the cup-up test configuration. Dish direct excitation tests were completed for various shaker locations with the antenna at the nominal $31.1 \mathrm{~N}$ catenary tension and $60 \mathrm{~Pa}$ inflation pressure. Then a frame excitation test was completed. These results were compared with the previous cupdown test configuration results. The direct dish excitation test results for the cup-up configuration produced almost identical mode shapes (Figure 16) and modal frequencies (Table 1) to those from the cup-down configuration. Slight differences in frequency can be due to a combination of small differences in pressure, catenary tension, and setup between tests. As with the cup-down tests, the cup-up tests also showed non-linearity in the form of shifting mode shape anti-nodes with shaker location. The frame excitation test in the cup-up configuration produced a major frame resonance mode $(17.6 \mathrm{~Hz})$ similar to the results from the cup-down test. 


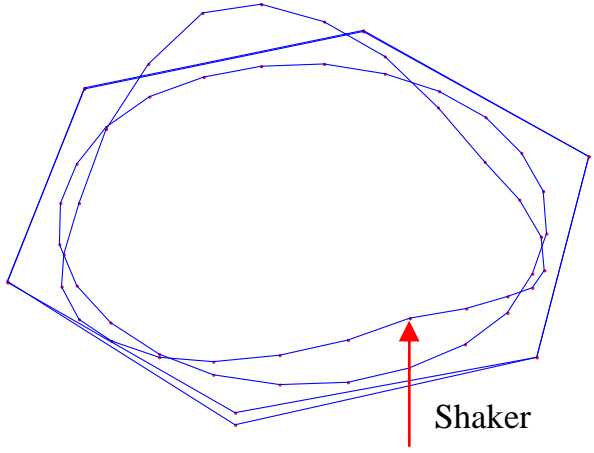

a) $9.0 \mathrm{~Hz} 2^{\text {nd }}$ Bending

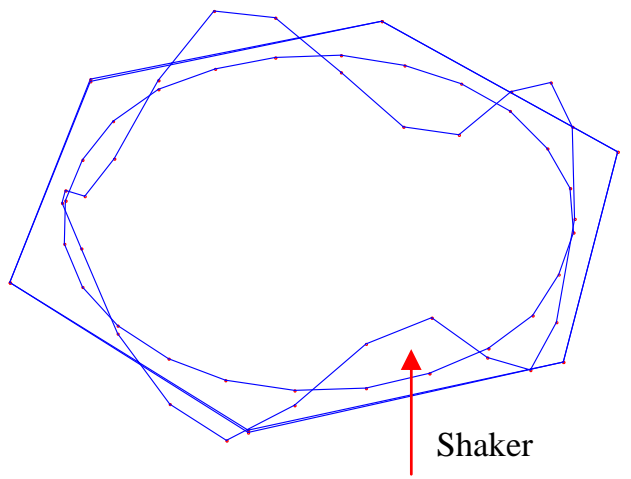

c) $10.9 \mathrm{~Hz} 4^{\text {th }}$ Bending

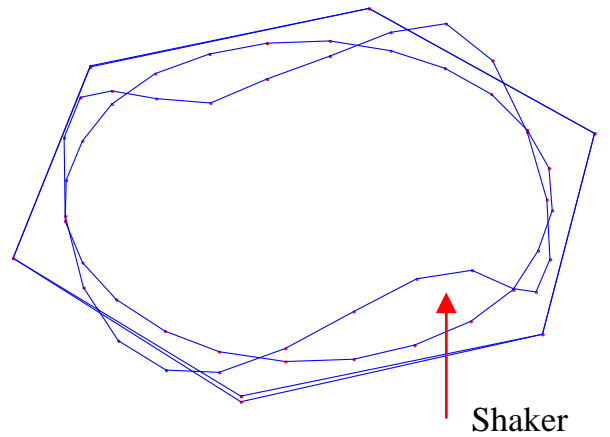

b) $9.9 \mathrm{~Hz} 3^{\text {rd }}$ Bending

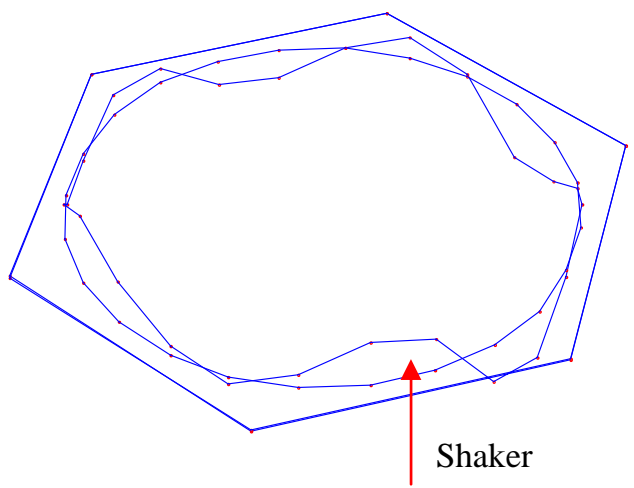

d) $12.5 \mathrm{~Hz}$ Dish Tilt with $5^{\text {th }}$ Bending

Figure 16: Low Spatial Resolution Test Mode Shapes

(Cup-Up Configuration)

Table 1: Dynamic Response Modes Description

(Cup-Down versus Cup-Up Configuration)

High Spatial Resolution Cup-Down Test versus Low Spatial Resolution Cup-Up Test

Nominal 31.1 N Catenary Tension, 60 Pa Pressure

\begin{tabular}{|c|c|c|l|}
\hline $\begin{array}{c}\text { Mode } \\
\#\end{array}$ & $\begin{array}{c}\text { Cup-Down } \\
\text { Freq, Hz }\end{array}$ & $\begin{array}{c}\text { Cup-Up } \\
\text { Freq, Hz }\end{array}$ & \multicolumn{1}{|c|}{ Mode Shape Description } \\
\hline 1 & 9.2 & 9.0 & $2^{\text {nd }}$ Dish Bending (taco mode) \\
\hline 2 & 9.9 & 9.9 & $3^{\text {rd }}$ Dish Bending \\
\hline 3 & 11.0 & 10.9 & $4^{\text {th }}$ Dish Bending \\
\hline 4 & 12.9 & 12.5 & Dish Tilt / with 5 \\
& - & 13.3 & \\
\hline 5 & 14.5 & 14.4 & Dish Tilt / with $6^{\text {th }}$ Dish Bending \\
\hline 6 & 16.8 & - & Slight Frame Tilt / Dish Tilt $/ 6^{\text {th }}$ Dish Bending \\
\hline 7 & 17.4 & 17.6 & Significant Frame Tilt / Dish Tilt $/ 7^{\text {th }}$ Dish Bending \\
\hline
\end{tabular}




\section{Frequency Variation with Inflation Pressure}

A sequence of testing was completed for the cup-up configuration to determine the variation in antenna system frequency with inflation pressure. The antenna was at the nominal $31.1 \mathrm{~N}$ catenary tension, but the pressure was varied from close to $0 \mathrm{~Pa}$ to $60 \mathrm{~Pa}$ in increments of $10 \mathrm{~Pa}$. Surprisingly, it was found that the $2^{\text {nd }}$ order dish bending mode frequency and shape did not change significantly with pressure indicating this mode is dominated by catenary tension rather than inflation pressure. The other higher order modes disappeared completely below 30 Pa pressure, as these modes are dependent on the inflation pressure (Figure 17). As pressure was increased the higher order modes would gradually appear in the data, although distorted at first and in many case repeated roots of the same order bending mode. For example at $10 \mathrm{~Pa}$, one $3^{\text {rd }}$ order bending mode appeared strongly along with numerous other distorted $3^{\text {rd }}$ order bending modes coupled with tilt motion. Not until $30 \mathrm{~Pa}$ did the $4^{\text {th }}$ and $5^{\text {th }}$ order bending modes appear strongly at $10.4 \mathrm{~Hz}$ and $11.9 \mathrm{~Hz}$. Once these modes appeared, they only increased in frequency slightly to $10.9 \mathrm{~Hz}$ and $12.5 \mathrm{~Hz}$ at $60 \mathrm{~Pa}$ pressure.

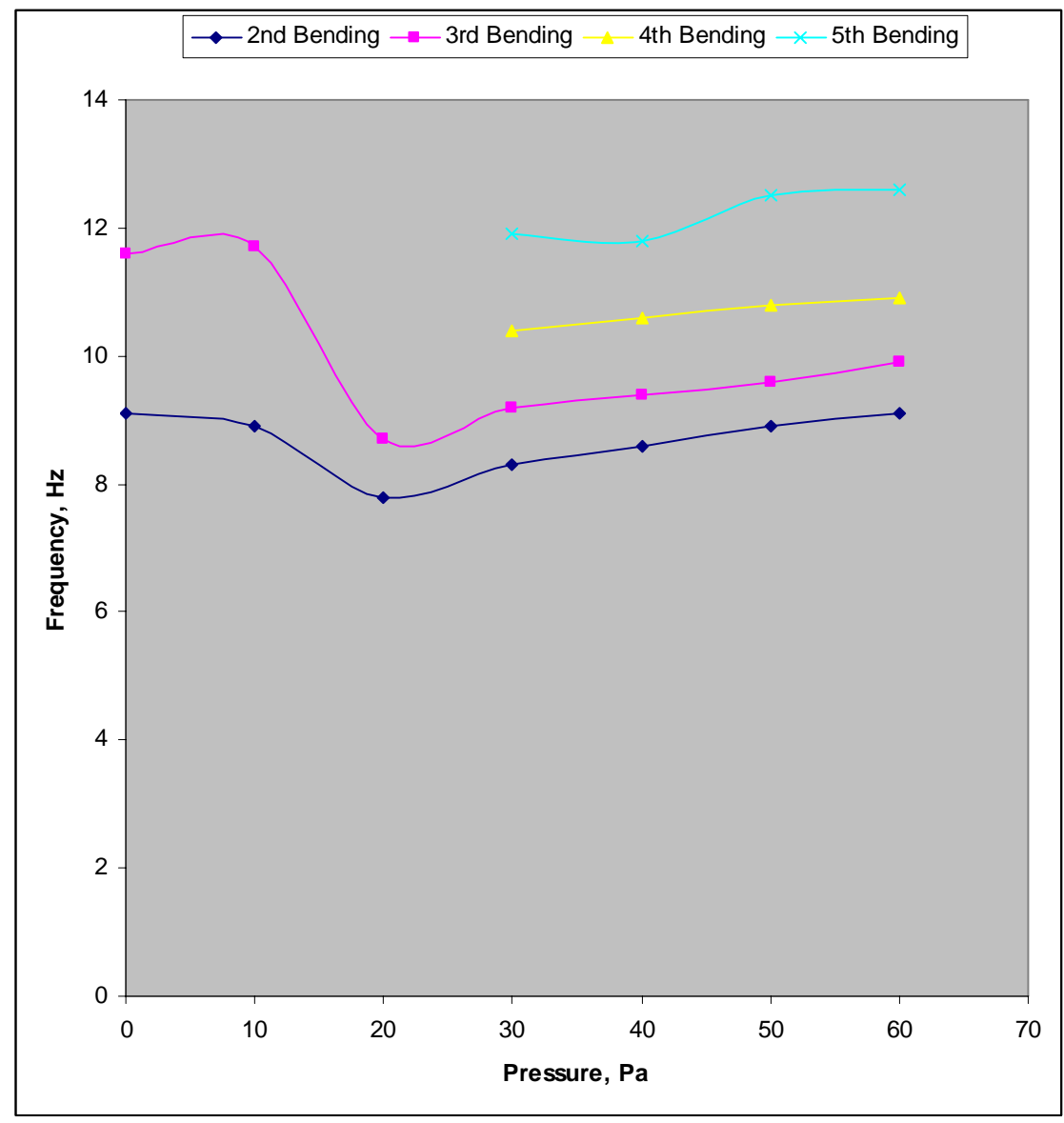

Figure 17: Frequency Variation with Inflation Pressure (Cup-Up Configuration) 


\section{Preliminary Structural Analysis}

\section{A. Finite Element Model}

A preliminary finite element model was developed for the pre-test structural analysis of the dish antenna (Figures 18 and 19). The upper canopy and lower bladder are inflated to aid in pushing the SMP composite layer into its ideal shape. The Center-partition transmits catenary load to the central hub. The catenaries hold the reflector membrane in tension. There are 25,218 elements of type quadrilateral and triangular shell elements, and 23,216 nodes in this finite element model. Initial modeling attempts were made with membrane elements in the Mylar portions (i.e. canopy, center-partition, and bladder) of the structure. However, significant convergence difficulties were encountered because of the local buckling (wrinkling) that occurs in the membrane elements. To further simplify the initial model development, a gross assumption was made that the frame was rigid as compared to the membrane structure. To simulate a rigid torus boundary condition, the dish was fixed to ground at the central hub and catenary tension was modeled by simply providing an applied nominal force of $31.1 \mathrm{~N}$ uniformly at each catenary location.

The static nonlinear finite element analysis of the parabolic reflector structure is performed with the ABAQUS program using the implicit analysis procedure. The reflector dish is inflated to an internal pressure load of $60 \mathrm{~Pa}$, and also subjected to gravity load to simulate the test conditions. The loading is applied in sequences with pressure load first, followed by gravity load, and then finally the tension load to the catenaries is applied. Normal mode vibration analysis is performed at the last converged nonlinear static analysis iteration to determine the natural frequencies and mode shapes of the antenna structure (see also Ref. 30).

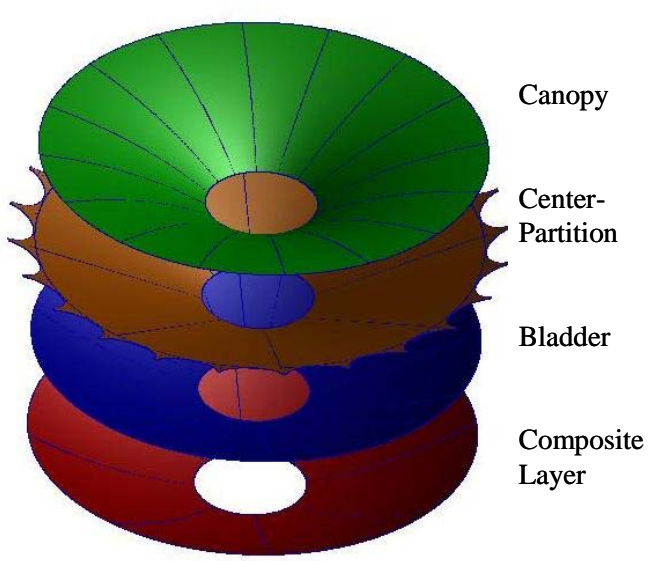

Figure 18: Major Components of Antenna Model

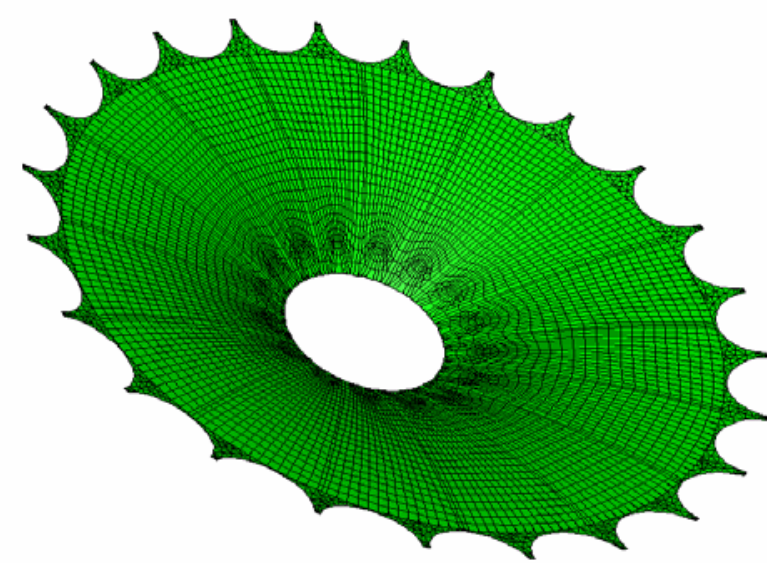

Figure 19: Fully Assembled Antenna Finite Element Model

\section{B. Normal Modes Analysis}

An initial normal modes analysis was performed to predict the frequency characteristics of the finite element model of the dish antenna. The updated stiffness matrix evaluated at the last iteration of the nonlinear static analysis and the mass matrix evaluated from the material mass density were used in the eigen-solution computation of the natural frequencies of the structure. The basic low frequency modes of the dish from this initial pre-test analysis are shown in the Figures 20 and 21. 


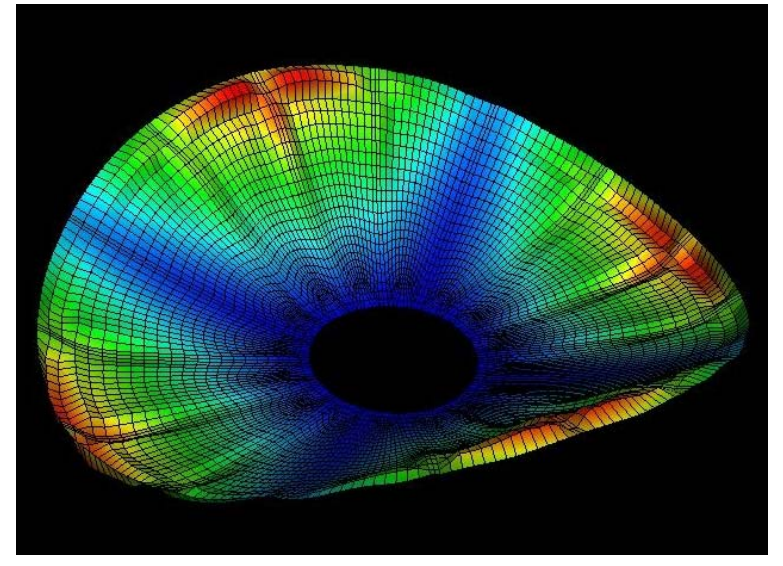

a) $49.9 \mathrm{~Hz} 2^{\text {nd }}$ Bending

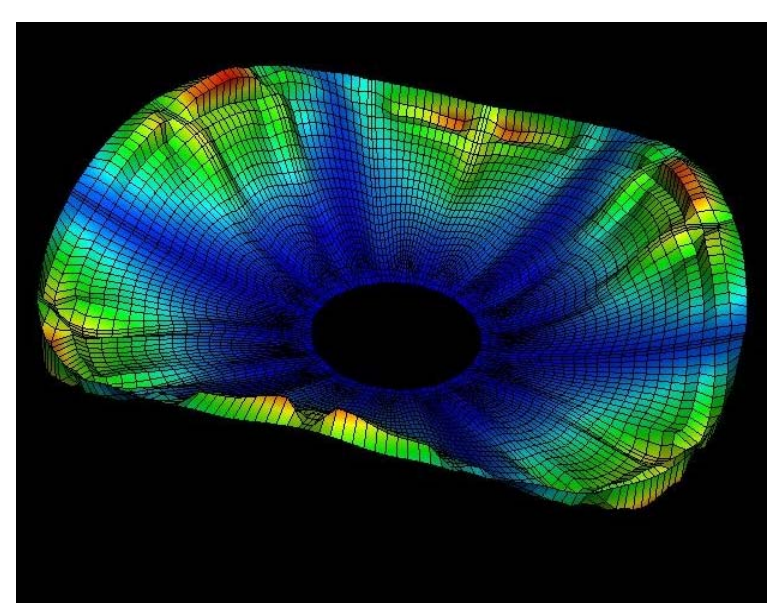

c) $71.3 \mathrm{~Hz}^{\text {rd }}$ Bending

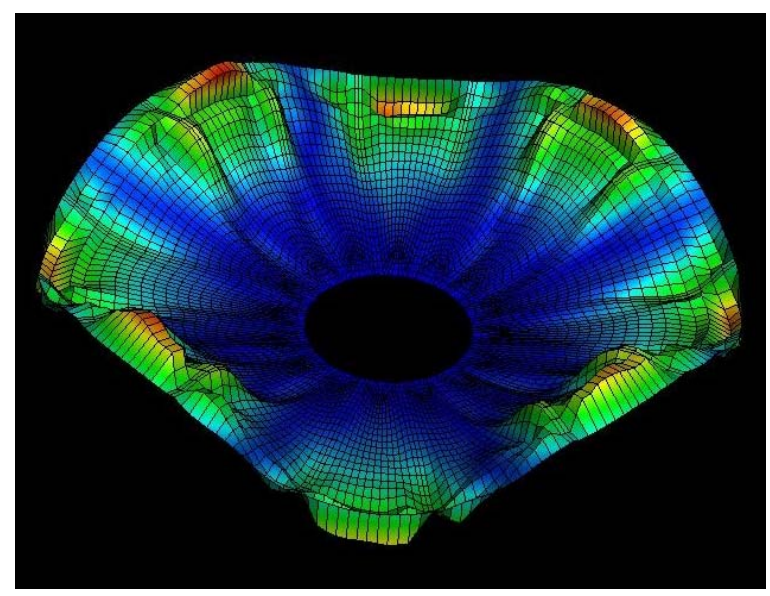

e) $88.6 \mathrm{~Hz} 4^{\text {th }}$ Bending

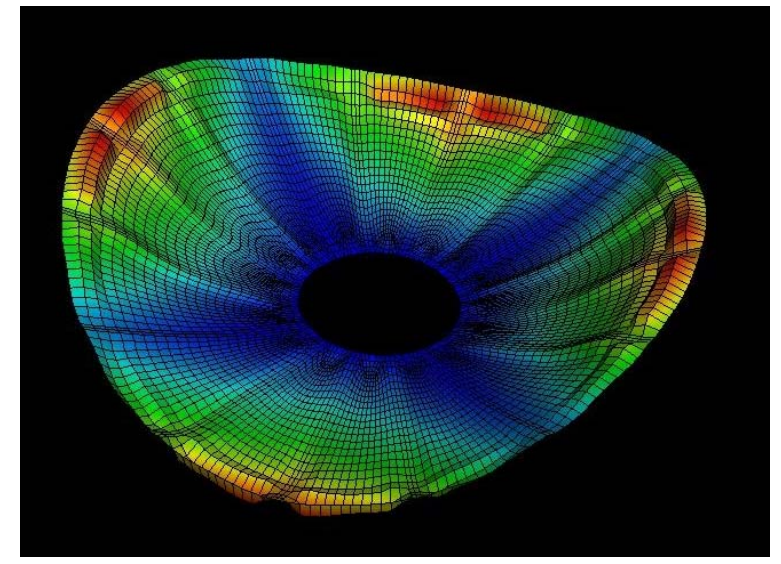

b) $52.1 \mathrm{~Hz} 2^{\text {nd }}$ Bending

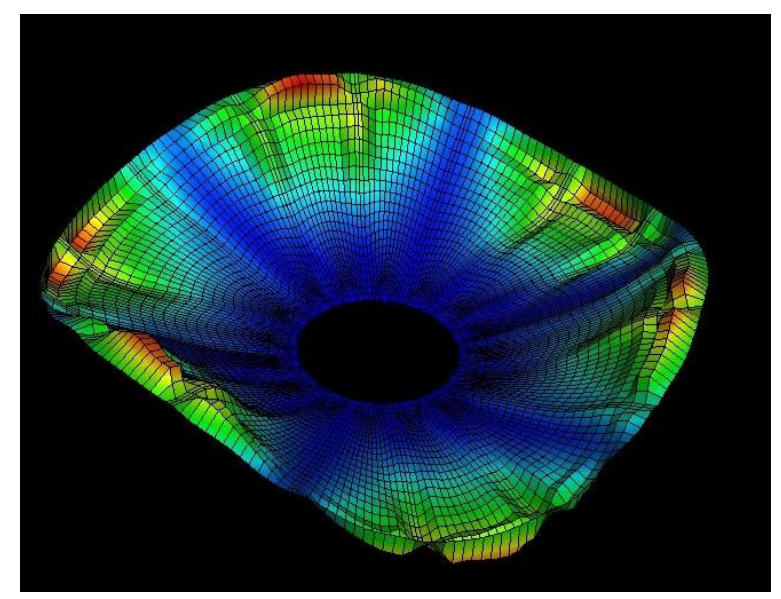

d) $71.9 \mathrm{~Hz}^{\text {rd }}$ Bending

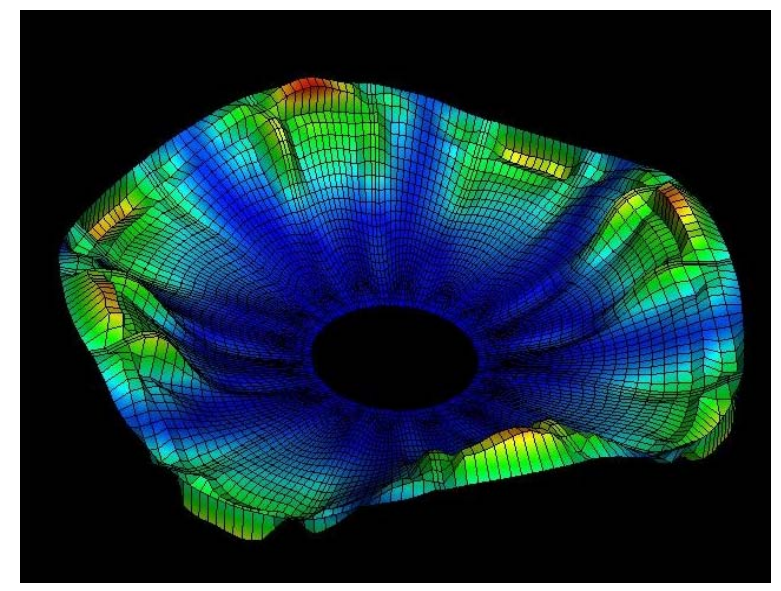

f) $88.7 \mathrm{~Hz} 4^{\text {th }}$ Bending

Figure 20: Analytical Mode Shapes that Correspond with Test 


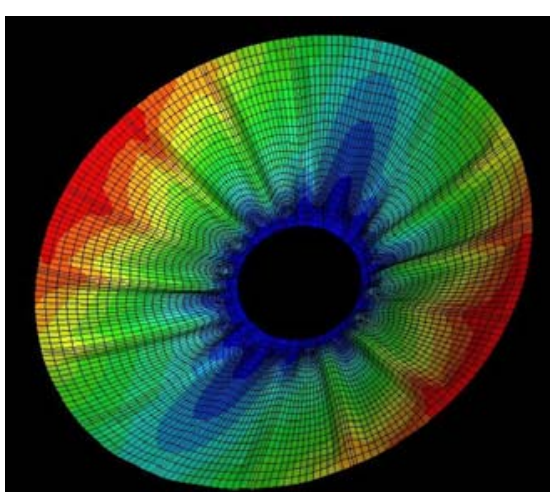

a) 41.0 Hz Tilt Mode

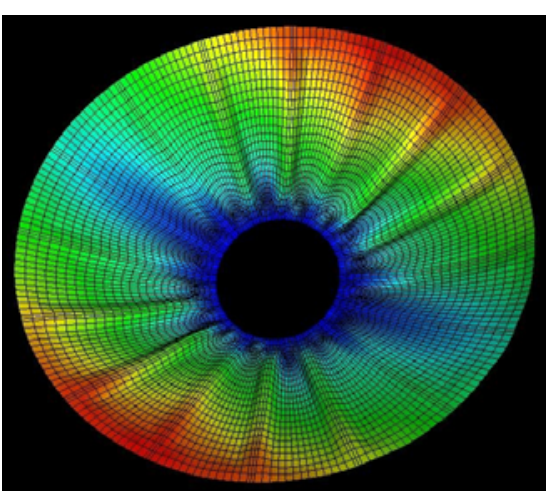

b) $41.1 \mathrm{~Hz}$ Tilt Mode

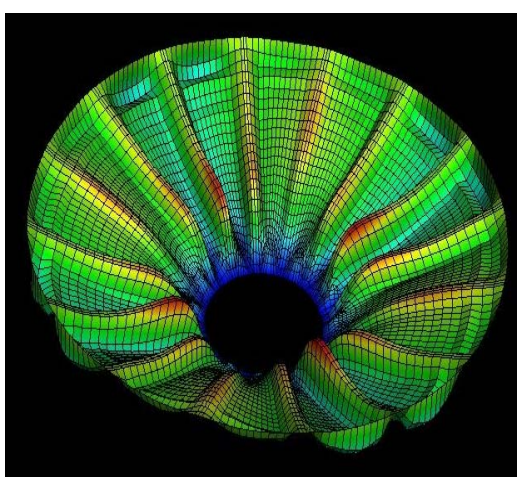

c) $69.7 \mathrm{~Hz}$ Octopus (Seam Mode)

Figure 21: Additional Analytical Mode Shapes

In looking at these results, many of the analytical mode shapes track quite consistently with the test results (Figures 20 and 11, respectively), but the frequencies from the pre-test analysis are considerably higher than the test results. Obviously, there is a major phenomena occurring in the test that is not accurately captured in the analysis. The most likely sources of error in the analysis are the perfect canopy shape (no wrinkles) and the rigid torus/uniform catenaries assumptions. At the time of this paper, the correlation activity had just begun; however, initial sensitivity studies were completed to investigate the potential impact of more accurate modeling to eliminate these assumptions (Table 2). During testing, non-linearities were identified that may be attributed to the catenary spring system and also to the wrinkles in the upper canopy (see Figure 22) that extended radially in all direction from the central hub structure. The wrinkles observed in the test article would have a tendency to lower the stiffness and bending around the circumference of the dish, thus bringing the resonant frequencies down from the analytically predicted values. A quick and simple study to simulate this reduced circumferential stiffness by reducing the bending modulus of the upper canopy by $50 \%$ resulted in a frequency reduction of $43.3 \%$ on the $2^{\text {nd }}$ bending mode. Based on these results, it is expected that refined analysis to better model the wrinkles would reduce the frequency further. Detailed studies to investigate the combined flexibility of the catenaries and torus have not been performed, but similar drops in predicted frequency are expected. Unfortunately, due to project re-scope no further sensitivity studies are currently planned.

Table 2: Antenna Frequency Sensitivity Study Via Simulation

\begin{tabular}{|c|c|c|c|}
\hline \multicolumn{4}{|c|}{$\begin{array}{c}\text { Frequency Sensitivity From Reference Case } \\
31.1 \mathrm{~N} \text { Catenary Tension } \\
50 \mathrm{~Pa} \text { Inflation Pressure } \\
49.2 \mathrm{~Hz} 2^{\text {nd }} \text { Bending }\end{array}$} \\
\hline \multirow[b]{2}{*}{ \# } & \multirow[b]{2}{*}{ Model Change } & \multicolumn{2}{|c|}{$2^{\text {nd }}$ Bending } \\
\hline & & $\begin{array}{l}\text { Freq } \\
(\mathrm{Hz})\end{array}$ & $\begin{array}{c}\% \\
\text { Diff. }\end{array}$ \\
\hline 1 & 1/2 Canopy Modulus & 28.2 & -43.3 \\
\hline 2 & 1/2 (Canopy \& Dish) Modulus & 22.1 & -55.5 \\
\hline 3 & $\begin{array}{l}\text { 1/2 (Canopy \& Dish) Modulus } \\
1 / 2 \text { Catenary Tension }\end{array}$ & 35.5 & -28.6 \\
\hline 4 & Double (Canopy \& Dish) Density & 35.1 & -29.4 \\
\hline
\end{tabular}

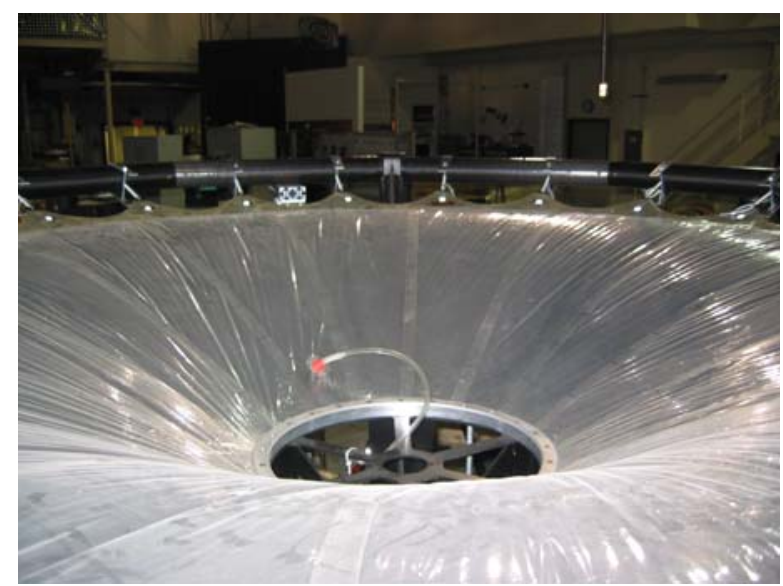

Figure 22: Wrinkles on Upper Canopy shown at 60 Pa Inflation Pressure 


\section{Concluding Remarks}

Tests were successfully completed to determine the structural characteristics of a 2-meter HIA test article. The static shape and modal dynamic response for the antenna were determined for two configurations in a gravity environment, first with the dish cup-up and then with the dish facing cup-down. Many dynamic tests were completed using various shaker positions, and the dynamic response was found to be very consistent and repeatable for both configurations for the fundamental modes. However, it was noted that the anti-nodes of all the mode shapes would consistently shift to be collocated with shaker position and this is an indication of a system non-linearity. This could be attributed to a combination of the catenary tension system and also to wrinkles in the upper canopy that extend radially from the center hub in all directions. These wrinkles reduce the bending stiffness around the circumference of the dish. It was found the first two fundamental modes ( ${ }^{\text {nd }}$ bending and $3^{\text {rd }}$ bending) are dominated by catenary tension and do not shift in frequency significantly with increased inflation pressure, whereas the $4^{\text {th }}$ and $5^{\text {th }}$ higher order modes are a result of the inflation stiffness of the system and will disappear if pressure drops below $30 \mathrm{~Pa}$. The pre-test analytical model produced mode shapes consistent with test, but the frequencies were significantly higher than measured. Initial studies suggest that more detailed modeling of the frame and canopy wrinkles are required to correlate the analysis with test results.

\section{References}

1. Anderson, L. J., Groth.,L.H.,"Reflector Surface Deviations in Large Parabolic Antennas,” IEEE Transaction on Antennas and Propagation, March , 1962.

2. Milliken, S. A., "The Development of High-Gain Deployable Antenna for Communication Satellites," AIAA 66-306, AIAA Communication Satellite System Conference, Washington D.C., May 1966.

3. Rusch, W. V. T., "The Current State of the Reflector Antenna Art," IEEE Transactions on Antennas and Propagation, Vol. AP-32, No.4, April, 1984.

4. Archer, J.S., "High Performance Parabolic Antenna Reflectors, J. of Spacecraft,” Vol. 17, No. 1, 1978.

5. Guastaferro, A., "A Technology Program for Large Space System", AIAA paper 79-0921, 1979.

6. Card, M. F., Boyer, W. J., "Large Space Structures,” Fantasies and Facts, AIAA paper 80-0674.

7. Hedgepeth, J. M., "Critical Requirements for the Design of Large Space Structures," NASA Contractor report -3484, Nov, 1981.

8. Friese, G. J., Bilyeu, G. D., Thomas, M., "Initial '80s Development of Inflated Antennas," L'GARDE Inc, NASA contractor report 166060, Jan. 1983.

9. Benton, B., " Thermal Control of Large Spacecraft Antenna Reflectors," AIAA-84-1777, AIAA 19th Thermophysics Conference, Colorado, 1984.

10. Campbell, T. G., Bailey, J. P., Belvin, K. W., "The Development of the 15-meter Hoop Column Deployable Antenna System with Structural and Electromagnetic Performance Results,” AIAA 86-0667, 1986.

11. Reaves, M. C., Belvin, K. W, and Bailey, J. P. ,"Finite-Element-Analysis Model and Preliminary Ground Testing of Controls-Structures Interaction Evolutionary Model Reflector,” NASA TM - 4293, May 1992.

12. Hedgepeth, J. M., "Interaction Between An Inflated Lenticular Reflection and Its Rim Support," AIAA95-1510-CP, 1995. 
13. Palisoc, A. L. and Huang, Y., "Design Tool For Inflatable Space Structures,” AIAA-97-1378, 1997.

14. Greschik, G., Palisoc, A., Cassapakis, C., Veal, G., and Mikulas, M. M., "Approximating Paraboloids with Axisymmetric Pressurized Membranes,” AIAA-98-2102, 1998.

15. Engberg, R. C., Lassitor, J. O.,"Modal Survey Test of the Soft 2x3 Meter Off-axis Inflatable Concentrator,” AIAA-2000-1639, 2000.

16. Moore, J., and McGee, J., "Design Optimization of Thin Film Solar Concentrators Using Non-Linear Deflection Modeling," AIAA-01-1422, 2001.

17. Pappa, R. S., Jones, T. W., Black, J. T., Walford, A., Robson, S., Shortis, M. R., "Photogrammetry Methodology Development for Gossamer Spacecraft Structures," $43^{\text {rd }}$ AIAA Conference, Denver, CO, AIAA-2002-1375, 2002.

18. Gaspar, J. S., Mann, T., Behun, V., Wilkie, W. K., Pappa, R., "Development of Modal Test Techniques for Validation of a Solar Sail Design,” AIAA-2004-1665, 2004.

19. Paxton, J., Hawk., C., "Material Property Effects on a Thin Film Solar Concentrator for Solar Thermal Propulsion," AIAA-94-3029.

20. Veal, G., Freeland, R., "In-step Inflatable Antenna Description,” AIAA conference, 1995.

21. Gierow P.A., Paxton, J. P., Cost, T. L. , Hawk, C. W., "Material Property Effects on a Thin-Film Concentrator,” Journal of Spacecrafts and Rockets, Vol.32, No.4, July 1995.

22. Moore, J. D., Bishop, J., "Evaluation of Catenary Suspension for Reducing Shape Errors In Inflated Solar Concentrators," AIAA-98-1985, 1998.

23. Pearson, J. C., Giewrow, P. A., Lester, D., "Near Term In-space Demonstration of an Inflatable Concentrator,” AIAA-99-1073, 1999.

24. Pappa, R. S., Lassiter, J. O., Ross, B. P., "Structural Dynamics Experimental Activities in Ultra-light weight and Inflatable Space Structures,” AIAA-2001-1263, 2001.

25. Willey, C. E., Schulze, R. E., Bakulic, R. S., Skullney, W. E., "A Hybrid Inflatable Dish Antenna System for Spacecraft,” AIAA-2001-1258, 42nd AIAA SDM conference, 2001.

26. Lin, J. K., Sapna, G. H., Scorborough, S. E., Lopez, B. C., "Advanced Precipitation Radar Antenna Singly Curved Parabolic Antenna Reflector Development," AIAA-2003-1651.

27. Pearson, J. C., Unroe, M. R., "Precision Tooling for Membrane Concentrators,” AIAA-2003-5174.

28. Belvin, K. W., "Ultra-light Weight Structures Technology for Space Solar Power," Space Communications Technical Interchange Meeting, Sept. 2002.

29. Belvin, W. K., "Advances in Structures for Large Space Systems," AIAA-2004-5898.

30. Sreekantamurthy, T., Gaspar, J. L., Mann, T., Behun, V., Pearson, J. C., Scarborough, S., “Nonlinear Structural Analysis Methodology and Dynamics Scaling of Inflatable Parabolic Reflector Antenna Concepts,” AIAA-2007-1834. 